American Journal of Pharmaceutical Education 2019; 83 (10) Article 7548.

\title{
RESEARCH
}

\section{Pharmapreneur - Defining a Framework for Entrepreneurship in Pharmacy Education}

\author{
T. Joseph Mattingly II, PharmD, MBA, PhD,,${ }^{\mathrm{a}, \mathrm{b}}$ Moaz Abdelwadoud, MD, ${ }^{\mathrm{a}}$ C. Daniel Mullins, PhD, ${ }^{\mathrm{a}}$ \\ Natalie D. Eddington, $\mathrm{PhD}^{\mathrm{a}}$ \\ ${ }^{\text {a }}$ University of Maryland School of Pharmacy, Baltimore, Maryland \\ ${ }^{\mathrm{b}}$ Editorial Board Member, American Journal of Pharmaceutical Education, Arlington, Virginia \\ Submitted February 6, 2019; accepted May 7, 2019; published December 2019.
}

\begin{abstract}
Objective. To determine the role of entrepreneurism within the broader missions of schools of pharmacy and develop an educational framework to produce pharmacist entrepreneurs.

Methods. Following a systematic review and six semi-structured interviews, a three-round Delphi process was conducted with an expert panel comprised of successful entrepreneurs, pharmacy faculty members and administrators, students, and community members. Participants were asked about the role of entrepreneurship in a pharmacy school's mission, how they would define a pharmacist entrepreneur, and to identify the knowledge, skills, and attitudes (KSAs) expected to be successful as a pharmacist entrepreneur. A model for entrepreneur education was also developed in accordance with Bloom's taxonomy. Participant agreement and rankings were reported.

Results. Based on the semi-structured interviews and the results from the Delphi process, the following framework for a pharmacist entrepreneur was proposed along with a list of KSAs: identifies, creates, and pursues new opportunities; successfully implements new ideas into practice; is willing to take risks; fills unmet needs; creates new value through innovation; is responsive to change; makes sacrifices; includes social and intrapreneurship; leverages existing knowledge, skills, and resources; goes beyond traditional roles for pharmacists; and improves patient care. Recommendations for entrepreneurship instruction, guided by Bloom's taxonomy of cognitive processes, were created.

Conclusion. According to our expert panel, a pharmacist entrepreneur combines several characteristics identified with a more traditional entrepreneur construct with the characteristics of an individual devoted to achieving outcomes beyond one's personal gain. Additional research to inform implementation and assessment of entrepreneurship within pharmacy curricula would provide more specific guidance for instructional design and accreditation evaluations.
\end{abstract}

Keywords: entrepreneur, knowledge, skills, attitudes, taxonomy

\section{INTRODUCTION}

What makes a pharmacist entrepreneur? We pose this question through the lens of pharmacy educators tasked with preparing future generations of pharmacists in accordance with the standards set by the Accreditation Council for Pharmacy Education (ACPE). ${ }^{1}$ One of the recommendations of the American Associations of Colleges of Pharmacy's (AACP) Academic Affairs Standing Committee was for the association to convene a "task force to develop outcomes related to traits in the affective domain such as self-efficacy, self-assessment, reflection, entrepreneurship, leadership and advocacy."2 The Center

Corresponding Author: Joey Mattingly, University of Maryland School of Pharmacy, 20 N. Pine St., N415, Baltimore, MD 21201. Tel: 410-706-8068. Email: jmattingly@rx.umaryland.edu. for the Advancement of Pharmacy Education (CAPE) subsequently developed a fourth iteration of educational outcomes created to guide curricular discussions for Doctor of Pharmacy (PharmD) programs that includes "Innovation and Entrepreneurship" within the new affective domain captured in Standard 4. As the Standards were updated, disagreement and controversy surrounding the instruction and assessment of outcomes for the traits identified in the affective domain have surfaced in the form of public criticisms from faculty, administrators, and students. ${ }^{4-6}$ Without agreement on a pharmacist entrepreneur definition and the knowledge, skills, and attitudes (KSAs) expected of graduates from accredited institutions, it is impossible to fairly assess schools and colleges of pharmacy on performance. This study aims to develop a framework for the pharmacist entrepreneur and 


\section{American Journal of Pharmaceutical Education 2019; 83 (10) Article 7548.}

identify specific KSAs to help guide instructional design and terminal learning objectives for this affective domain trait.

\section{METHODS}

This study incorporated a multi-step process (Figure 1) to gather information from different sources to inform the final pharmacist entrepreneur framework. A systematic literature review was conducted using SCOPUS, EMBASE, and PubMed in accordance with the Preferred Reporting Items for Systematic Reviews and Meta-Analyses guidelines previously published. ${ }^{7}$ In addition to the systematic review, semi-structured interviews were conducted with six pharmacy-related entrepreneurs to inform the initial round of the Delphi process. The six experts chosen for the indepth interviews were not included in 30 invited panelists for the Delphi process.

In-depth interviews were conducted to help obtain a clearer understanding of the subject, determine areas to investigate, and inform the initial Delphi panel questionnaire. Semi-structured open-ended questions were used for maximum probing of issues, perspectives, and concepts about the role of entrepreneurship in pharmacy education and the skills necessary to be a successful pharmacist entrepreneur. Interviews were conducted inperson and via telephone in order to maximize rapport and facilitate candor. The experts invited to participate were identified from multiple sources including a recent publication of profiles of pharmacy entrepreneurs, the University of Maryland Board of Visitors, and through networks established by the University of Maryland's Associate Dean of Development and Alumni Affairs. ${ }^{8}$ These experts were chosen on the basis of lived experience leading new business development in a pharmacy-related field. Audio recordings were collected and transcribed through Rev (San Francisco, CA), with advance permission from the subject to ensure that answers were clear, unambiguous, and recorded correctly. Subjects were able to review the final transcripts for accuracy before final analysis. Interview data were analyzed using thematic analysis from a grounded theory approach, a flexible method which identifies commonalities and differences in qualitative data clustered around themes derived directly from the text in the transcripts. ${ }^{9,10}$

The panel was comprised of a heterogeneous group of pharmacy school stakeholders with an interest in achieving the study purpose: pharmacy school instructors, faculty members, and administrators with a special interest or expertise in entrepreneurial education; pharmacy students or recent graduates; and patients or community members. Panelists were identified through literature searches, pharmacy organization networks, referrals from people initially contacted, and the research team's network from previous work on entrepreneurship. The research team sought diversity in experiences and profiles but did not specify a minimum proportion for each stakeholder group or demographic characteristic. However, given the relevance of the study aims to instructional design and sourcing of experts from peerreviewed literature, the research team relied more heavily on panelists representing the first category (instructors, faculty members, and administrators with a special interest or expertise in entrepreneurial education). Panelists maintained full anonymity so that comments could be made freely without attribution. A minimum panel response rate for a completed round was set at a two-thirds majority, or 20 of the 30 invited panelists.

The first Delphi round was used to develop the initial base of knowledge, focused on open-ended questions informed by the literature review and preliminary interviews. Round 1 included optional demographic questions as well as a request for permission to acknowledge the individuals by name in the final manuscript. Panelists were asked to define a pharmacist entrepreneur, describe how entrepreneurship fits within the mission and vision of schools of pharmacy, discuss the most effective methods of teaching entrepreneurship, and identify fundamental KSAs for pharmacist entrepreneurs. Themes from round 1 were developed independently by two authors and coded using NVivo, version 12 (QSR International Pty Ltd., Burlington, $\mathrm{MA})$. Once an agreement with the themes was reached, statements were formed and a round 2 questionnaire was developed.

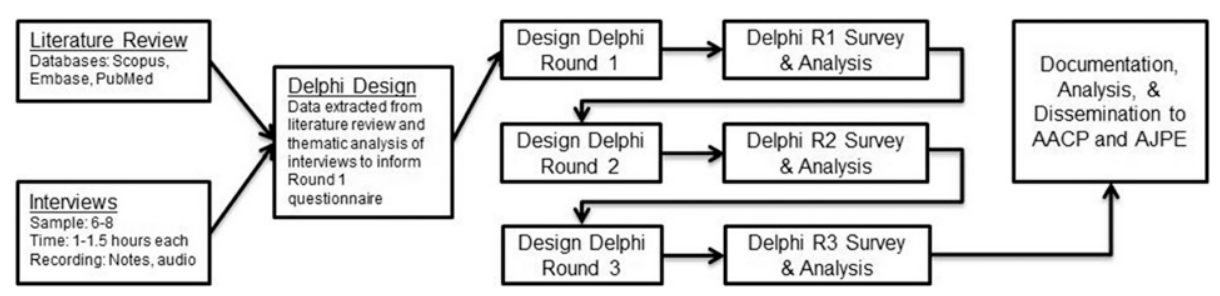

Figure 1. Framework for a Research Study on Entrepreneurship in Pharmacy Education that Included a Systematic Review, Structured Interviews, and a Delphi Process 


\section{American Journal of Pharmaceutical Education 2019; 83 (10) Article 7548.}

The second round of Likert-type questions sought panel agreement with each statement, with an a priori agreement level set at $\geq 75 \%$. Statements in the second round were grouped into the definition of a pharmacist entrepreneur, the importance of entrepreneurship in the mission and vision of a school, the importance of entrepreneurship in a pharmacy school's curriculum, effective approaches for teaching entrepreneurship to pharmacy students, the fundamental KSA's identified, and a proposed taxonomy for pharmacy entrepreneurship education developed from Bloom's taxonomy framework. ${ }^{1,12}$

Statements that reached panel agreement in round 2 were carried forward. In the third round, panelists were asked to rank each item within each category. Mean ranking and level of agreement for quantitative rankings were assessed using Kendall's coefficient of concordance calculated in RStudio, Version 1.1.383 (RStudio, Inc., Boston, MA).

\section{RESULTS}

Six expert pharmacy-related entrepreneurs agreed to 60-90 minute in-person or telephonic interviews between May and August 2018. All interviews were recorded, transcribed, and reviewed by each expert prior to qualitative analysis for accuracy. Only one of the transcribed interviews received edits pertaining to the spelling of names, but no other content was revised. The themes that emerged pertaining to the role of entrepreneurship in pharmacy education included the future of pharmacy, pharmacy horizons beyond traditional roles, the importance of inclusion in the mission and vision of a school of pharmacy, creating an entrepreneurial culture, and social entrepreneurism. Educational approach themes included systematic inclusion in the curriculum, exposure to other industries or disciplines, mentoring opportunities, and intended recruitment and selection of students and faculty members interested in entrepreneurship. Specific skills desired in an entrepreneur as determined by the experts were categorized as business management, accounting, marketing ideas, specialization or niche development, creativity, innovation, networking, and risk management. Additionally, themes for the personal characteristics of an entrepreneur emerged, including curiosity, motivation, personal life balance, and readiness.

Following Delphi panel recruitment, 29 (97\%) of the 30 panelists who initially agreed to serve on the panel responded to the round 1 survey. The panel included 16 $(55 \%)$ men and $13(45 \%)$ women with an average age of 47 years ( \pm 11 years). The open responses produced 15 statements pertaining to the definition of a pharmacist entrepreneur, three statements for the importance of entrepreneurship in a school's mission and vision, four statements related to entrepreneurship in the curriculum, six approaches for teaching entrepreneurship, and lists for potential KSAs (Tables 2 and 3). From the open responses, the study team created statements applicable to each of the cognitive process dimensions of Bloom's taxonomy (Figure 1).

Round 2 sought agreement from the panel on all of the statements, identified KSAs, and proposed taxonomy for pharmacist entrepreneur education. With 25 (83\%) participants responding, at least 19 of the 25 participants were required to agree or strongly agree to achieve the $\geq 75 \%$ threshold determined a priori. Agreement was achieved for all items in the proposed taxonomy (Figure 1) at a level of $88 \%$ or higher. Items that failed to reach the predetermined agreement threshold are identified in Table 2 and Table 3. None of the statements pertaining to entrepreneurship in the school's mission and vision and the importance of entrepreneurship in the curriculum achieved the desired level of agreement.

As in round 2, $25(83 \%)$ of the 30 invited participants responded to the round 3 questionnaire, which focused on ranking each of the items within each category. Full rankings for items within the educational approach, knowledge, skills, and attitudes categories are listed in Table 4. Ranking order for the educational approach statements were better correlated than the KSA rankings, but still between "weak" and "moderate" levels for ranking consensus. ${ }^{13}$

\section{DISCUSSION}

\section{Defining a Pharmacist Entrepreneur}

According to our expert panel, a pharmacist entrepreneur combines several characteristics identified with a more traditional entrepreneur construct with the characteristics of an individual devoted to achieving outcomes beyond his or her personal gain. Lumpkin and Dess describe entrepreneurial orientation in terms of five

Table 1. Characteristics of Participants on a Delphi Panel Conducted as Part of a Research Study to Define Entrepreneurship in Pharmacy Education $(\mathrm{N}=29)$

\begin{tabular}{lc}
\hline Characteristic & No. (\%) \\
\hline Sex & \\
$\quad$ Male (\%) & $16(55.2)$ \\
Mean age in years (SD) & $47(11)$ \\
Relationship to school (\%) & \\
$\quad$ Instructor/Faculty/ Administrator & $18(62.1)$ \\
Alumni & $4(13.8)$ \\
Community Member & $3(10.3)$ \\
Student & $2(6.9)$ \\
Other & $2(6.9)$ \\
\hline
\end{tabular}


American Journal of Pharmaceutical Education 2019; 83 (10) Article 7548.

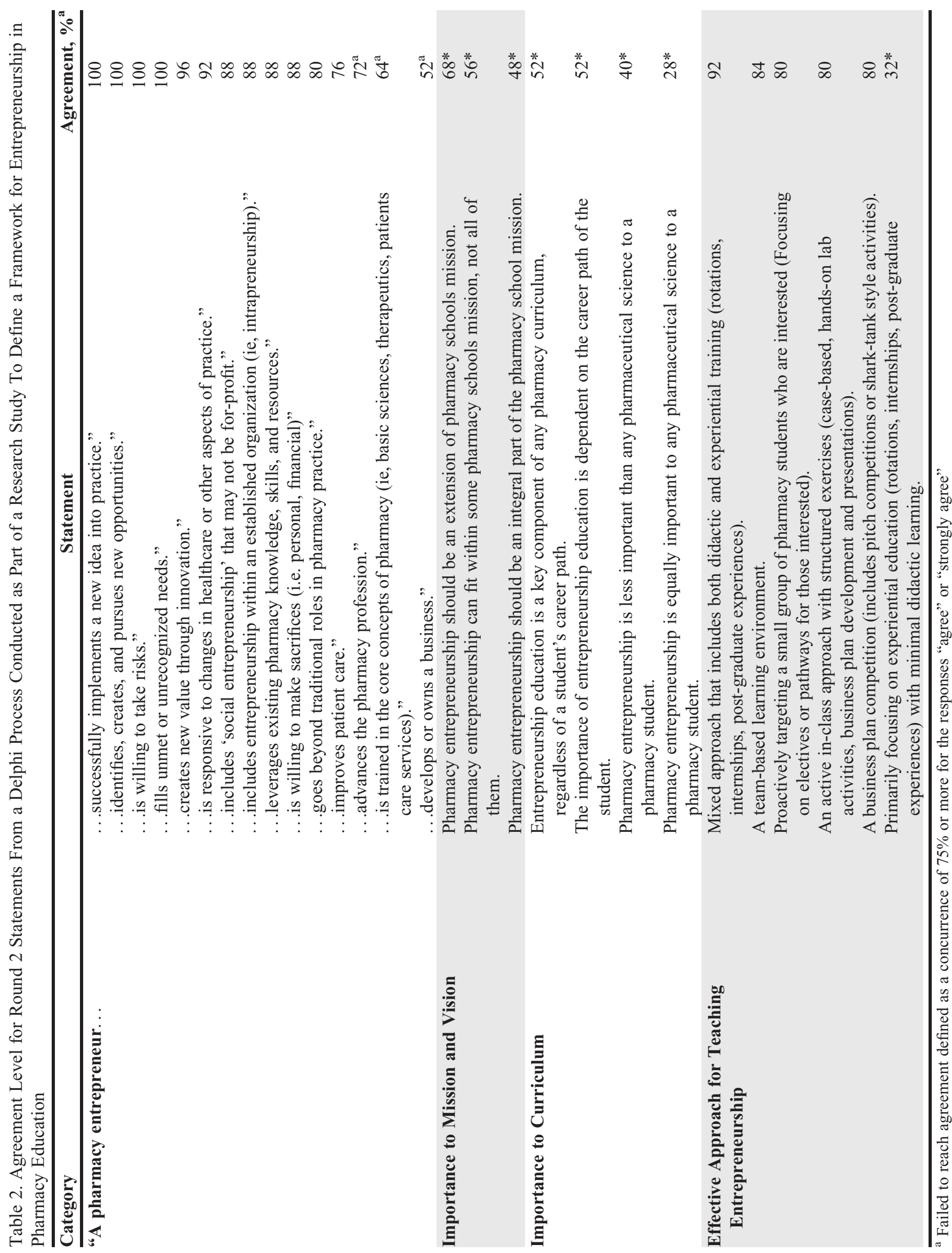


American Journal of Pharmaceutical Education 2019; 83 (10) Article 7548.

Table 3. Agreement Level for Round 2 Items in a Delphi Study to Identify the Characteristics That Define a Pharmacist Entrepreneur

\begin{tabular}{|c|c|c|c|c|c|}
\hline Knowledge & $\begin{array}{c}\text { Agreement } \\
(\%)^{\mathrm{a}}\end{array}$ & Skill & $\begin{array}{c}\text { Agreement } \\
(\%)^{\mathrm{a}}\end{array}$ & Attitude & $\begin{array}{c}\text { Agreement } \\
(\%)^{\mathrm{a}}\end{array}$ \\
\hline Business Plan Development & 100 & Communication & 100 & Innovative & 100 \\
\hline Strategy & 100 & Teamwork & 100 & Resilient & 100 \\
\hline Project Management & 100 & Dealing With Failure & 100 & Determined & 100 \\
\hline Legal & 100 & Risk Assessment & 100 & Flexible & 100 \\
\hline Health System & 96 & Problem-Solving & 100 & Futuristic & 100 \\
\hline Leadership & 96 & Adaptability & 100 & Risk-Taking & 96 \\
\hline Innovation Cycle & 96 & Leadership & 96 & Curious & 96 \\
\hline Communication & 96 & Negotiation & 96 & Responsible & 96 \\
\hline Accounting & 88 & Self-Assessment & 96 & Passionate & 92 \\
\hline Implementation Science & 88 & Organization Skills & 92 & Proactive & 92 \\
\hline Finance & 84 & Market Analysis & 92 & Positive & 92 \\
\hline Human Resources & 84 & Networking & 92 & Courageous & 88 \\
\hline Sales \& Marketing & 80 & Business Plan Development & 92 & Change Agent & 84 \\
\hline Pharmacy Core & 76 & Sales \& Marketing & 88 & Intrinsically Motivated & 84 \\
\hline Information Systems & $72^{a}$ & Finance (Applied) & 84 & Trustworthy & 84 \\
\hline \multirow[t]{9}{*}{ Research Methods } & $60^{\mathrm{a}}$ & Managing People & 84 & Collaborative & 80 \\
\hline & & Patient Care & $72^{a}$ & Energetic & 76 \\
\hline & & Data Analysis & $68^{\mathrm{a}}$ & Reflective & 76 \\
\hline & & Technology & $68^{\mathrm{a}}$ & Self-Restraint & $68^{\mathrm{a}}$ \\
\hline & & Research Methods & $56^{\mathrm{a}}$ & Empathetic & $56^{\mathrm{a}}$ \\
\hline & & & & Culturally Sensitive & $56^{\mathrm{a}}$ \\
\hline & & & & Outgoing & $56^{\mathrm{a}}$ \\
\hline & & & & Altruistic & $40^{\mathrm{a}}$ \\
\hline & & & & Humble & $32^{\mathrm{a}}$ \\
\hline
\end{tabular}

${ }^{a}$ Failed to reach agreement, which was defined as a concurrence of $75 \%$ or more for the responses agree or strongly agree

dimensions: autonomy, innovativeness, risk-taking, proactivity, and competitive aggressiveness. ${ }^{14}$ The pharmacist entrepreneur definition proposed as a result of this study (Figure 3) captures four of those five domains, only omitting competitive aggressiveness. Competitive aggressiveness refers to an entrepreneur directly challenging others in a marketplace to gain position or market share. ${ }^{14}$ While not included in our final definition, principles of strategy related to market analysis and competition were identified by our panel as essential knowledge and skills needed for a pharmacist entrepreneur.

The 2010-2011 AACP Academic Affairs Standing Committee described the entrepreneurship trait as one that revolves around taking on the risks and responsibilities associated with implementing innovations. ${ }^{15}$ Additionally, the committee considered critical thinking and problemsolving foundational components and cited Rubino and Freshman's eight entrepreneurship competency clusters (decision making, strategic thinking, risk-taking, confidence building, communicating ideas, motivating team members, tolerance of ambiguity and internal locus of control) as potential areas for development for pharmacist entrepreneurs. ${ }^{15,16}$ The CAPE's 2013 Educational Outcomes reinforced Rubino and Freshman's competency clusters and further specified entrepreneurship recommendations to "engage in innovative activities by using creative thinking to envision better ways of accomplishing professional goals." This study's proposed definition of a pharmacist entrepreneur encompasses the CAPE recommendation and expands the construct to give pharmacy educators more guidance.

\section{Approaches Effective for Entrepreneurship Education}

Our expert panel ranked a mixed instructional approach (didactic and experiential) as the most important process for educating pharmacist entrepreneurs. While didactic lectures were recognized for some of the foundational knowledge items, the panel ranked active-learning methods highly supporting the use of structured exercises, team-based projects, and business plan competitions. Additionally, the panel found value in proactively targeting students with greater interests in entrepreneurship with more advanced elective opportunities.

\section{Knowledge, Skills, and Attitudes}

This study adds a comprehensive list of KSAs ranked in order of importance for pharmacy educators to consider during the instructional design process (Table 4). The 
American Journal of Pharmaceutical Education 2019; 83 (10) Article 7548.

Table 4. Final Rankings in a Research Study to Define Entrepreneurship in Pharmacy Education

\begin{tabular}{|c|c|c|c|}
\hline Rank & Item & Mean Rank (SD) & $W^{\mathbf{a}}$ \\
\hline & Educational Approach & & \\
\hline 1 & Mixed Didactic \& Experiential & $1.8(1.3)$ & .4 \\
\hline 2 & Active In-Class with Structured Exercises & $2.7(1.2)$ & \\
\hline 3 & Proactive Targeting (Electives) & $3.3(1.5)$ & \\
\hline 4 & Team-Based Exercises & $3.6(1.3)$ & \\
\hline \multirow[t]{2}{*}{5} & Business Plan Competition & $3.7(1.1)$ & \\
\hline & Knowledge & & \\
\hline 1 & Communication (oral, written, interpersonal, etc) & $3.4(3.1)$ & .3 \\
\hline 2 & Business Plan Development & $4.8(2.3)$ & \\
\hline 3 & Health System (system literacy) & $5.3(4.1)$ & \\
\hline 4 & Strategy Principles (market analysis, competition, etc) & $5.4(2.7)$ & \\
\hline 5 & Leadership & $6.9(4.1)$ & \\
\hline 6 & Laws \& Regulations & $7.3(3.3)$ & \\
\hline 7 & Innovation Cycle & $7.8(3.8)$ & \\
\hline 8 & Project Management & $8.1(4.1)$ & \\
\hline 9 & Finance (securing financing, capital, etc) & $8.4(2.8)$ & \\
\hline 10 & Accounting (balance sheets, income statements, etc) & $8.7(3.3)$ & \\
\hline 11 & Pharmacy Core (basic sciences, patient care, etc) & $9.1(5.0)$ & \\
\hline 12 & Sales \& Marketing & $9.1(3.6)$ & \\
\hline 13 & Human Resource Management & $10.3(3.4)$ & \\
\hline \multirow[t]{2}{*}{14} & Implementation Science & $10.6(3.0)$ & \\
\hline & Skills & & \\
\hline 1 & Communication (oral, written, interpersonal, etc) & $2.2(1.8)$ & .3 \\
\hline 2 & Problem-solving & $5.4(4.3)$ & \\
\hline 3 & Business Plan Development & $5.6(2.5)$ & \\
\hline 4 & Networking & $5.7(3.7)$ & \\
\hline 5 & Adaptability & $6.4(4.3)$ & \\
\hline 6 & Leadership & $7.2(4.7)$ & \\
\hline 7 & Dealing with Failure & $7.9(3.6)$ & \\
\hline 8 & Organization Skills & $9.1(4.0)$ & \\
\hline 9 & Market Analysis & $9.3(4.9)$ & \\
\hline 10 & Teamwork & $9.5(4.1)$ & \\
\hline 11 & Self-assessment & $10.2(4.0)$ & \\
\hline 12 & Sales \& Marketing & $10.3(3.1)$ & \\
\hline 13 & Finance (Applied - managing and raising money) & $11.3(3.9)$ & \\
\hline 14 & Managing People & $11.4(3.6)$ & \\
\hline 15 & Risk Assessment & $12.2(2.9)$ & \\
\hline \multirow[t]{2}{*}{16} & Negotiation & $12.2(3.3)$ & \\
\hline & Attitudes & & \\
\hline 1 & Resilient & $4.3(3.7)$ & .3 \\
\hline 2 & Determined & $5.7(3.2)$ & \\
\hline 3 & Positive & $6.2(4.4)$ & \\
\hline 4 & Risk-taking & $6.5(4.0)$ & \\
\hline 5 & Innovative & $9.6(4.0)$ & \\
\hline 6 & Flexible & $8.1(3.6)$ & \\
\hline 7 & Passionate & $8.1(3.8)$ & \\
\hline 8 & Futuristic & $8.4(3.9)$ & \\
\hline 9 & Change Agent & $8.6(4.2)$ & \\
\hline 10 & Curious & $9.0(5.2)$ & \\
\hline 11 & Proactive & $9.6(4.0)$ & \\
\hline 12 & Trustworthy & $11.1(4.6)$ & \\
\hline 13 & Reflective & $11.4(4.4)$ & \\
\hline
\end{tabular}


American Journal of Pharmaceutical Education 2019; 83 (10) Article 7548.

Table 4. (Continued)

\begin{tabular}{llc}
\hline Rank & \multicolumn{1}{c}{ Item } & Mean Rank (SD) $^{\mathbf{a}}$ \\
\hline 14 & Intrinsically Motivated & $11.6(5.2)$ \\
15 & Responsible & $13.4(4.3)$ \\
16 & Energetic & $13.7(4.4)$ \\
17 & Courageous & $13.8(4.3)$ \\
18 & Collaborative & $15.1(4.2)$ \\
\hline
\end{tabular}

${ }^{a}$ Kendall's coefficient $(W)$ calculated to evaluate confidence in ranks

ability to communicate effectively (oral, written, and interpersonal) was ranked the most important item identified both as knowledge and a skill. This supports the use of written and oral presentations throughout the curriculum and may demonstrate how many other pharmacy courses indirectly benefit the future pharmacist entrepreneur. Developing a business plan was also ranked highly as foundational knowledge and a skill. Schools may consider engaging with the National Community Pharmacists Association for guidance related to business plan development given the organization's history of running a national business plan competition specifically for student members. ${ }^{17}$

Several foundational knowledge areas overlap with the knowledge students should be gaining in existing pharmacy management courses. These areas relate to items often taught in masters programs in business management such as strategy, project management, finance, accounting, marketing, and human resource management. Dual PharmD/Master of Business Administration (MBA) programs capture these topic areas in more depth, but our panel did not explicitly recommend that the pharmacist entrepreneur have an MBA or equivalent education. Previous research related to dual PharmD/MBA degree-earning students found that the majority of graduates entered the pharmaceutical industry, chain pharmacy, hospital/institutional, or managed care pharmacy. ${ }^{18}$ Business management programs may be helpful to gain the foundational knowledge and skills frequently identified with entrepreneurs, but evidence from a sample of these dual degree students suggests the motivation stems from a desire to be more competitive in an existing job market rather than to create new business opportunities. ${ }^{19}$

Leadership was also identified as foundational knowledge as well as a skill necessary for entrepreneurs, which CAPE identified in its own subsection of the 2013 Educational Outcomes. ${ }^{3}$ Our panel found several characteristics typically identified with multiple leadership frameworks important for entrepreneurs. Items such as adaptability, self-assessment, dealing with failure, and communication are all consistent with different models of leadership. $^{20,21}$ Other items identified such as health system literacy and pharmacy core sciences demonstrate how being competent in pharmacy is necessary (by definition) to be a successful pharmacist entrepreneur.
In terms of attitudes, the concept of failure may be closely tied to several highly ranked characteristics for a pharmacist entrepreneur. Resiliency, determination, positivity, and risk-taking were the four most important attitudes identified in this study, which may all be linked to different stages of (before, during, and after) failure. During the semi-structured interviews and round 1 open response analysis, several experts recognized the ability to bounce back from failure as a critical attitude for any future entrepreneur. Our experts recognized failure as part of the process and being resilient to failure as a necessity. If the potential for failure is viewed through an optimistic lens, then one may be more predisposed to greater risktaking. Gaining experience through failure (or multiple failures) may be valuable for the pharmacist entrepreneur, however, the pharmacy education apparatus does not support this type of learning. An old adage, "C equals PharmD," has been passed down to many students over the past two decades. This embodies the notion that anything but failure within the formal curriculum of a school of pharmacy will be rewarded with the doctoral hood. Failure within a single pharmacy class may lead to the probation or expulsion of a student as they have not demonstrated the mastery of the course objectives deemed necessary to eventually become a pharmacist. One could argue that the environment created to educate pharmacists to meet the competency standards to practice pharmacy directly inhibits the growth of an environment that encourages a "try-fail-and-try-again" approach. We are not advocating or encouraging student failures in core pharmacy classes, but simply calling for more opportunities embedded throughout the curriculum where students may experiment with new ideas without the fear that failure could end (or stall) their pharmacy career.

\section{Entrepreneurship Education for Pharmacists Ap- plied to Bloom's Taxonomy}

For schools and colleges of pharmacy considering curricular development or integration of entrepreneurship education, we propose a framework combining the cognitive processes identified in Bloom's taxonomy with specific application to entrepreneurship (Figure 2). As faculty develop instructional plans, we recommend using 


\section{American Journal of Pharmaceutical Education 2019; 83 (10) Article 7548.}

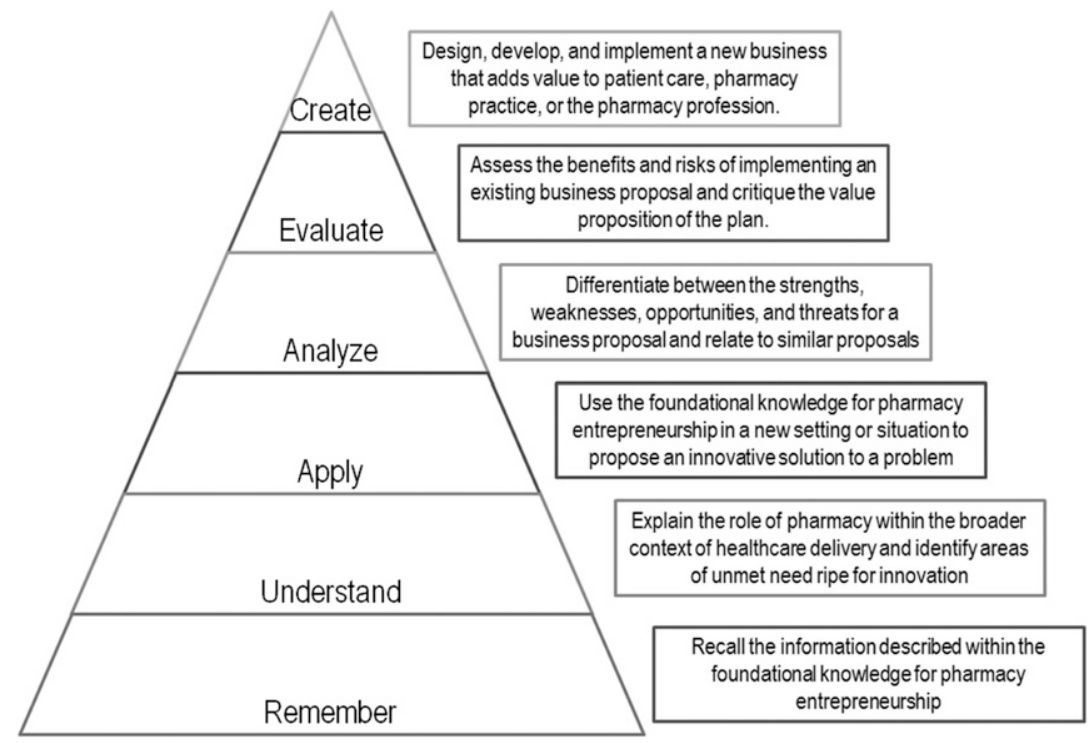

Figure 2. Bloom's Taxonomy Applied to Entrepreneurship Education for Pharmacists

didactic lectures to cover foundational knowledge components (remember function of Bloom's taxonomy) and to explain the role of pharmacy within the broader context of healthcare so that students may begin to identify areas of unmet need (understand function). Within these didactic classes, we recommend incorporating structured exercises that allow students to use the newly acquired knowledge in new settings, forcing them to propose an innovative solution to a problem (apply function). Teambased activities may be preferred for these structured activities based on the feedback from our Delphi study. Examinations may be helpful to assess how well students are able to differentiate between strengths, weaknesses, opportunities, and threats for a given business proposal (analyze function) and to critique the value proposition of the business idea (evaluate function). While on rotation or through other experiential opportunities (summer internship or fellowship), students should be tasked with activities that cover the apply, analyze, and evaluate functions. Depending on the length of the experience, the students may have the opportunity to help preceptors design, develop, and implement a new business idea that adds value to patient care, practice, or the pharmacy profession (create function). It may be difficult for most students to reach the create function while in pharmacy school, because implementation of the business plan may be time consuming for a full-time student. Engaging in business plan competitions or other proposal development activities may help capture the rest of the create domain; however, students must recognize that more

\section{A pharmacist entrepreneur...}

...identifies, creates, and pursues new opportunities,

...successfully implements new ideas into practice,

...is willing to take risks,

... fills unmet or unrecognized needs,

...creates new value through innovation,

...is responsive to changes in healthcare, markets, or other aspects of pharmacy practice,

...is willing to make sacrifices,

...includes social entrepreneurship and intrapreneurship,

...leverages existing pharmacy knowledge, skills, and resources,

...goes beyond traditional roles in pharmacy practice, and...

...improves patient care.

Figure 3. Proposed Definition for the Pharmacist Entrepreneur Construct 


\section{American Journal of Pharmaceutical Education 2019; 83 (10) Article 7548.}

learning will be achieved through doing or executing the plan.

\section{Place in the Strategic Plan and Curriculum}

Given our higher threshold for panel agreement, none of the statements developed from our Delphi related to the importance of entrepreneurship inclusion in a school's mission or curriculum reached $\geq 75 \%$. While multiple items did meet a $\geq 50 \%$ threshold, these statements clearly did not resonate with everyone on the panel. During the six in-depth interviews with experienced entrepreneurs, the consensus was that entrepreneurship was vital to a school's mission and vision as the interviewees felt that entrepreneurship would be necessary for the profession to survive and advance. While this sentiment was shared by several Delphi panel members, there was still hesitancy to make a firm statement that entrepreneurship should be an integral part of a school's strategic plan. We recommend that deans, faculty members, students, and other key institutional stakeholders consider how the entrepreneurship construct may fit within their current educational environment before making it a formal component of the school's mission and vision. Considering the ACPE Standards, schools must address entrepreneurship within the curriculum to meet Standard 4 , but our study reveals that several experts are not on board with the notion that entrepreneurship must be in the curriculum for a PharmD program. ${ }^{1,3}$ We recommend further discussion at the AACP-level to hear dissenting opinions or concerns with curricular inclusion.

In a Delphi process, the selection of appropriate experts may be the most challenging step that researchers must consider in terms of bias. ${ }^{22}$ We focused on successful entrepreneurs for the semi-structured in-depth interviews to build the first round of the Delphi, but then we purposefully recruited a large proportion of panelists with direct ties to academia as an instructor or administrator $(62 \%)$ who had demonstrated interest in entrepreneurship education. While we felt this was appropriate to gain the opinions of pharmacy educators, results may have been different if we had focused solely on recruiting a panel of experienced entrepreneurs. Another limitation of our Delphi process involves the more stringent definition of panel agreement at $\geq 75 \%$. This definition was chosen to be more selective and to include only the items where a supermajority agreed, but it is important for readers to consider those items in Tables 2 and 3 that were mentioned by multiple panelists but failed to meet the $a$ priori threshold. For example, attitudes representing empathy, humility, altruism, and cultural sensitivity were mentioned during the in-depth interviews as well as the first Delphi round, but were not included in the final set. If we had focused our Delphi recruitment solely on social entrepreneurs, we believe that these attitudes would have been more widely accepted. We have presented all items for the sake of transparency as well as to encourage other researchers to explore whether constructs with less agreement in our panel should be examined further.

\section{CONCLUSION}

Through semi-structured interviews with experienced entrepreneurs and a multi-round Delphi process, a framework for entrepreneurship education applied to pharmacy was proposed along with an extensive list of KSAs expected for successful pharmacist entrepreneurs. The panel also produced a consensus definition of a "pharmacist entrepreneur" to help guide both accreditors and schools as they work to address the requirements for formal evaluation and quality improvement of instructional design. Additional research to inform implementation and assessment of entrepreneurship within pharmacy curricula would provide more specific guidance for instructional design and accreditation evaluations.

\section{ACKNOWLEDGMENTS}

With permission, the research team would like to thank the following individuals for their participation in the semi-structured interviews: Congressman Earl "Buddy" Carter, Victoria Hale, Tom Menighan, Navneet Puri, Ellen Yankellow, and George Zorich. We would also like to thank the following experts who served on the Delphi panel and agreed to be publicly acknowledged: Audra Stinchcomb, Beth Martin, Gayle Brazeau, Brian Ung, David Holdford, Kenneth Hohmeier, Diana Courtney, Donald Klepser, Jay Shah, Jeff Cain, Justin Gatwood, Kevin Rodondi, Kayce Shealy, Lynette Bradley-Baker, Randy McDonough, Michelle Farland, Matt Murawski, Nathan Pope, Pastor Frank Lance, Prasun Subedi, Stacey Curtis, Stephen Eckel, Sally Huston, Alan Spies, Tara Feller, Theresa Tolle, Timothy Baker, and Edwin Oak.

Financial Disclosure: This research was supported by a New Investigator Award from the American Association of Colleges of Pharmacy

\section{REFERENCES}

1. Accreditation Council for Pharmacy Education. Accreditation standards and key elements for the professional program in pharmacy leading to the doctor of pharmacy degree ("Standards 2016"). https:// www.acpe-accredit.org/pharmd-program-accreditation/. Published 2015. Accessed June 21, 2018.

2. Mason HL, Assemi M, Brown B, et al. Report of the 2010-2011 academic affairs standing committee. Am J Pharm Educ. 2011;75(10):Article S12. 


\section{American Journal of Pharmaceutical Education 2019; 83 (10) Article 7548.}

3. Medina MS, Plaza CM, Stowe CD, et al. Center for the Advancement of Pharmacy Education Educational Outcomes 2013. Am J Pharm Educ. 2013;77(8):Article 162. doi:10.5688/ajpe778162. 4. Fjortoft N. The challenge of the Accreditation Council for Pharmacy Education's standard four: identifying, teaching, measuring. Am J Pharm Educ. 2016;80(5):Article 73. doi:10.5688/ ajpe 80573.

5. Pham J. A student's perspective on assessment and the affective domain. Am J Pharm Educ. 2015;79(8):Article 125. doi:10.5688/ ajpe 798125 .

6. Fuentes DG, Whitney Caudill JD, Henriksen JA, Smith T. The CAPE outcomes revisions should not require drastic changes to pharmacy curricula. Am J Pharm Educ. 2014;78(1):Article 20. doi:10.5688/ajpe78120.

7. Mattingly II TJ, Mullins CD, Melendez DR, Boyden K, Eddington ND. Entrepreneurship in pharmacy practice and education: a systematic review. Am J Pharm Educ. 2019;83(3):Article 7233. doi:10.5688/ajpe7233.

8. Zorich GS. Entrepreneurs in Pharmacy: And Other Leaders. Outskirts Press, Inc; 2018.

9. Gale NK, Heath G, Cameron E, Rashid S, Redwood S. Using the framework method for the analysis of qualitative data in multidisciplinary health research. BMC Med Res Methodol. 2013;13:117. doi:10.1186/1471-2288-13-117.

10. Garson GD. Grounded Theory. 2016 Edition. Asheboro, NC: Statistical Associates Publishers; 2016.

11. Bloom BS, Englehard MD, Furst EJ, Hill WH, Krathwohl DR. Taxonomy of Educational Objectives: The Classification of Educational Goals. Vol 16;1956. doi:10.1300/J104v03n01_03.

12. Pickard MJ. The new Bloom's Taxonomy: an overview for family and consumer sciences. J Fam Consum Sci Educ.

2007;25(1):11. doi:10.1021/BI0623025.
13. Schmidt RC. Managing delphi surveys using nonparametric statistical techniques. Decis Sci. 1997;28(3):763-774. doi:10.1111/ j.1540-5915.1997.tb01330.x.

14. Lumpkin GT, Dess GG. Clarifying the entrepreneurial orientation construct and linking it to performance. Acad Manag Rev. 1996;21(1):135-172. doi:10.2307/258632.

15. Mason HL, Assemi M, Brown B, et al. Report of the 2010-2011 academic affairs standing committee. Am J Pharm Educ. 2011;75(10):Article S12. doi: 10.5688/ajpe7510S12.

16. Rubino L, Freshman B. Developing entrepreneurial competencies in the healthcare management undergraduate classroom. J Health Adm Educ. 2005;22(4):399-416. http:// www.ncbi.nlm.nih.gov/pubmed/16485785.

17. National Community Pharmacists Association. Good Neighbor Pharmacy NCPA Pruitt-SchutteStudent Business Plan Competition. https://www.ncpanet.org/students/chapter-operations/business-plancompetition. Accessed January 20, 2018.

18. Daly CJ, Tierney SEL, O'Brien E, Fiebelkorn KD, Jacobs DM. Career progression of the pharmacy/MBA professional: characterization and perceptions of the combined degree. Am J Pharm Educ. 2017;81(4):Article 72. doi:10.5688/ajpe81472. 19. Jacobs DM, Daly CJ, Tierney S-EL, O'Brien E, Fiebelkorn KD. Current attitudes and perceptions of dual pharmd/mba degree program students. Am J Pharm Educ. 2017;81(4):Article 71. 20. Avolio BJ, Gardner WL. Authentic leadership development: getting to the root of positive forms of leadership. Leadersh $Q$. 2005;16(3):315-338. doi:10.1016/j.leaqua.2005.03.001.

21. Gardner WL, Cogliser CC, Davis KM, Dickens MP. Authentic leadership: a review of the literature and research agenda. Leadersh Q. 2011;22(6):1120-1145. doi:10.1016/j.leaqua.2011.09.007.

22. Hsu C, Sandford B. The delphi technique: making sense of consensus. Pract Assessment, Res Eval. 2007;12(10):1-8. doi:10.1016/S0169-2070(99)00018-7. 